\title{
Validation of Zone Models: Entrainment rates and Convective Heat Losses from Model Atria Tests
}

\author{
O. ISHINO and T. TANAKA \\ Building Research Institute \\ Japan
}

\author{
M. A. DELICHATSIOS \\ Factory Mutual Research Corporation \\ Norwood, MA 02062 USA
}

\section{ABSTRACT}

Detailed experiments of smoke layer development in Atria revealed the need for refining the relationships for 1) air entrainment rates into low Froude number (large diameter) pool fires, and 2) the convective heat transfer coefficient to the walls. Experiments were conducted in a square cross section enclosure $2 \mathrm{~m} \times 2 \mathrm{~m} \times 5 \mathrm{~m}$ high having adjustable size openings near the bottom (for the fresh air supply) and at the ceiling (for smoke exhaust) (see Fig. 1). Steady state conditions were established prior to the measurements for methane pool fires produced by a $30 \mathrm{~cm}$ diameter sand box burner at two heat release rates, $10 \mathrm{~kW}$ and $20 \mathrm{~kW}$, and various combinations of inlet and outlet vent sizes. Temperature measurements by a vertical thermocouple rack were used to determine the height of the smoke layer. Exhaust flow rates were precisely measured by using the tracer gas method, which in the present experiments included two gases: $\mathrm{CO}_{2}$ and $\mathrm{O}_{2}$ (simultaneous co measurements showed no detectable carton monoxide levels, i.e., the combustion was complete). The pressure difference distribution and the neutral plane were determined by differential pressure transducers along the enclosure height. The redundancy and accuracy of the measurements in this project were essential for the development and establishment of a new entrainment relationship for the buoyant plume of low Froude number (large diameter) pool fires; the normalized entrainment rate varies proportionally to $2 / D$, as it was proposed in a previous publication $(3)$. Moreover, the convective heat transfer coefficient can be determined by using a constant Stanton number, while currently used correlations in. zone models failed to reproduce the experimental results (1).

Keywords: Entrainment, Convective Heat Flux, Zone Models in Atria.

\section{INTRODUCTION}

Buildings having atria have become increasingly popular in recent years, because of the charm and the comfort offered by those atria to building spaces. However, concern exists that smoke may spread rapidly and widely in a building through an atrium in the event of fire. Despite this, rational methodologies and standards for fire safety for such buildings have not yet been well established in the current building regulations.

In order to prevent smoke spreading through an atrium to the adjacent floor areas, it is necessary that the partitions, including the glazing, have a 


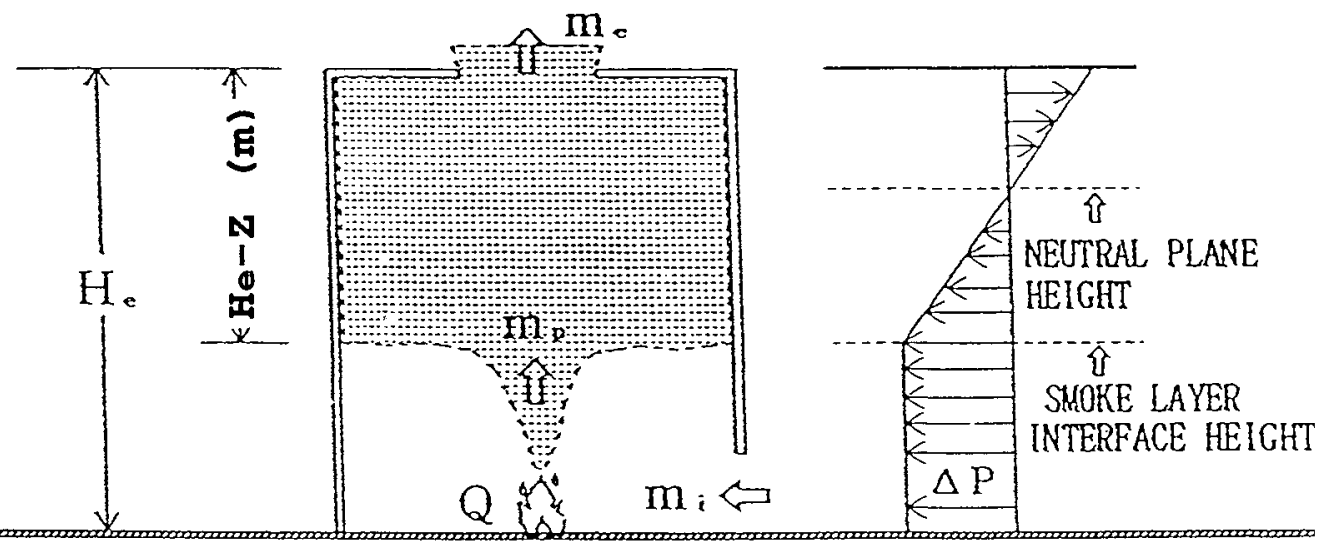

Figure 1. The atrium space conditions at a steady state. 
certain level of heat resistant performance so that they will not be broken by the exposure to the hot smoke layer caused by possible fire, and that the partitions are sufficiently air tight or the atrium space is kept at negative pressure relative to the pressures of the floor areas.

In addition, it is necessary to keep the clear height at a certain level in case the area or the geometry of an atrium is such that it may cause great difficulty for firefighters to put out fires without endangering their lifes by entering into the atrium.

In this study, the validity of the simple two layer zone model (1), developed to investigate the efficiency of smoke control effect by natural venting, is examined by experiments (1) using a model atrium where the effects of heat release rate of fire, smoke vent area and air inlet area are investigated (1).

The agreement of the two layer zone model with the experiments is not so good regarding predictions of smoke layer depth and smoke layer temperature. This discrepancy is attributed to the inapplicability of standard plume entrainment and heat transfer relationships $(1,2)$ to this problem. By using the detailed experimental results from this study, new correlations are developed for a) (thermal) plume entrainment in an intermediate regime, and b) natural convective heat transfer to the walls of a compartment.

\section{EXPERIMENTAL SETUP AND MEASUREMENTS}

A steady state experiment in a small scale model atrium, $2.0 \mathrm{~m} \times 2.0 \mathrm{~m} \times$ $5.0 \mathrm{~m}$ (height), as shown in Figure 1, has been designed for a) measuring heat losses, entrainment, hot layer temperatures and neutral plane location; and b) validating two layer zone models. Both the exhaust opening area and the inlet area could be varied during the tests. A collection hood was placed $.3 \mathrm{~m}$ above the ceiling for measuring heat release rates and exhaust mass flow rates by recording $\left(\mathrm{CO}_{2}\right)$ species concentrations both inside the hot layer and inside the hood exhaust pipe (1). A circular methane gas burner $.3 \mathrm{~m}$ in diameter was placed $.5 \mathrm{~m}$ above the floor to avoid blowdown of the fire plume owing to the opening jet from the air inlet. The following test conditions were applied (total 48 tests):

Heat Release Rate $(\mathrm{kW}): 10.0,20.0$

Smoke Vent Area $\left(\mathrm{m}^{2}\right): \quad .04, .09, .16$

Opening Area Ratio: $\quad 8,6,4,2,1,1 / 2,1 / 3,1 / 4$

(smoke vent area over inlet area).

A detailed set of experimental measurements were taken: (a) temperature profiles in the hot layer; b) vertical pressure distribution; c) species $\left(\mathrm{O}_{2}, \mathrm{CO}_{2}, \mathrm{CO}\right)$ concentration inside the hot layer and inside the collecting hood. The detailed, carefully collected results have been presented in a previous paper by Ishino and Tanaka (1).

A simple two layer model based on standard entrainment and heat transfer relationships $(1,2)$ failed to reproduce the experimental results and trends. Figures 2 and 3 show a comparison of predictions from this model (1) with the present experiments: Eigure 2 plots the smoke layer average temperature and Figure 3 plots the smoke layer interface height at steady state conditions and for varying opening area ratio (smoke vent area) air 


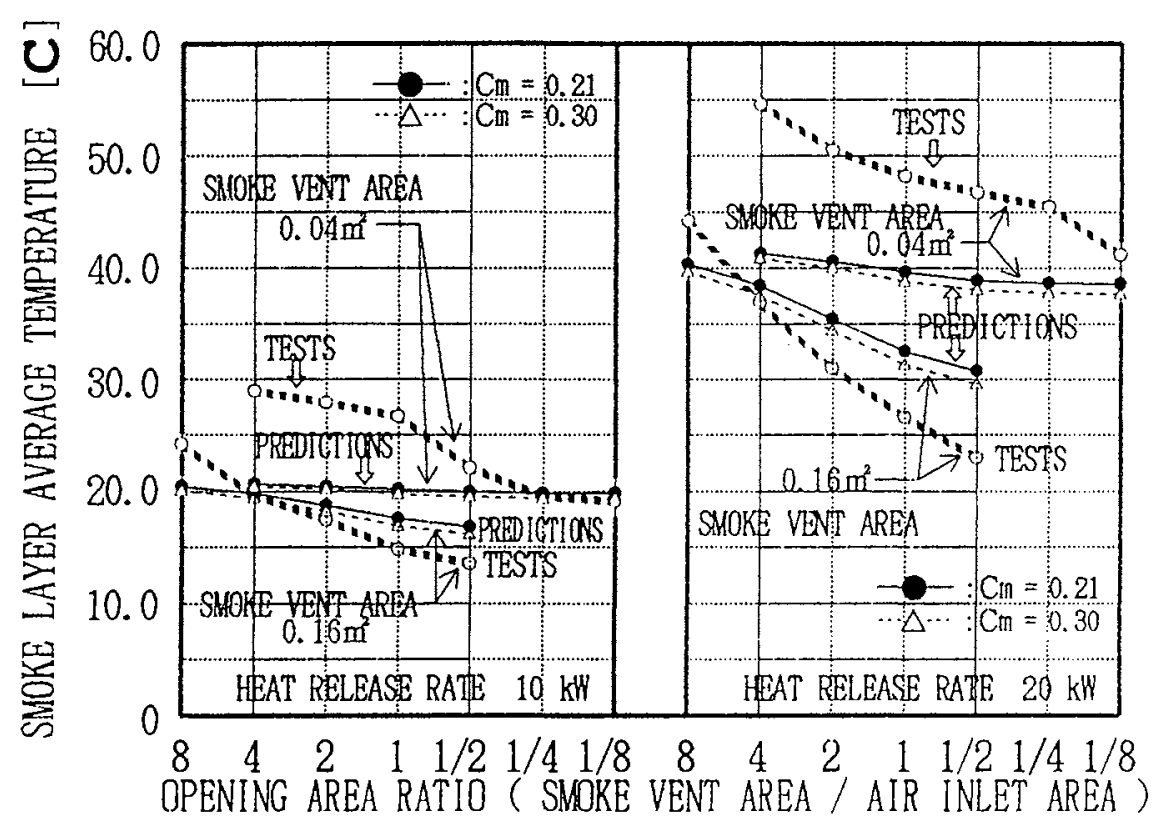

Figure 2. Predicted and measured steady state smoke layer temperatures for various opening area ratios. Predictions have been made for two values of the entrainment coefficient $C_{m}=.21$ and $C_{m}=.30$ (see Eq. (1)). 


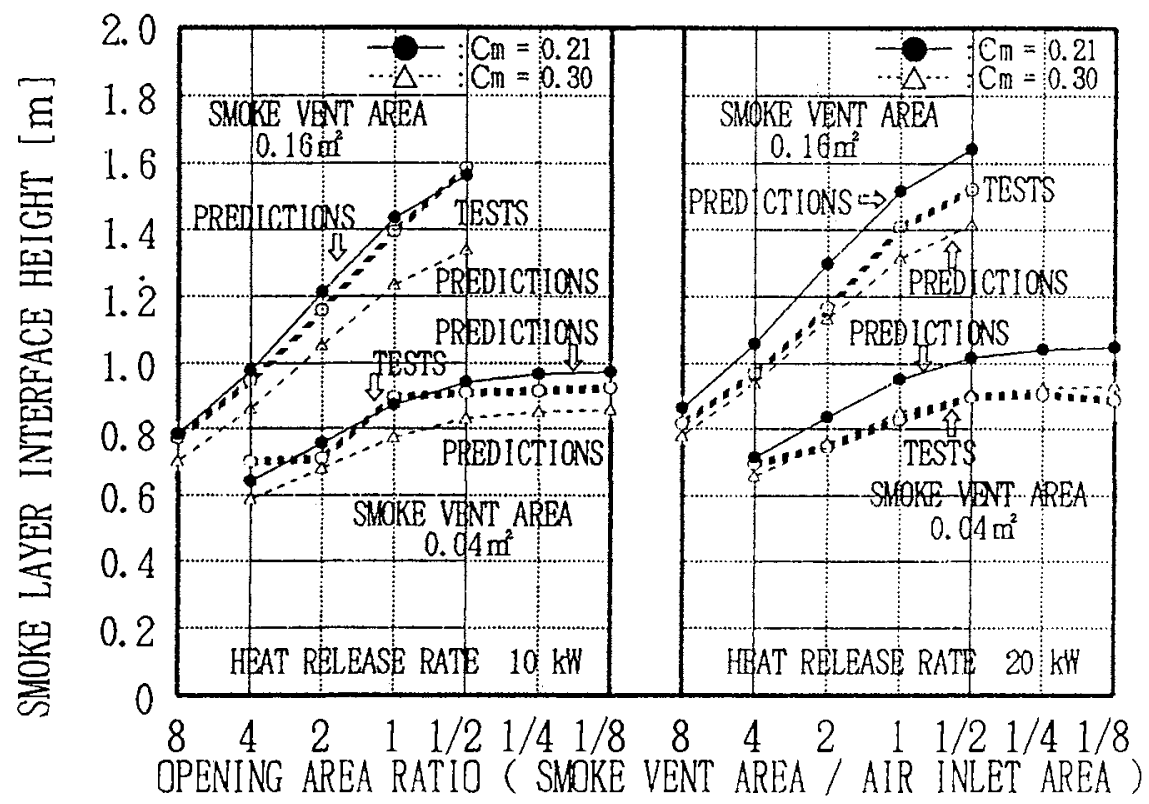

Eigure 3. Predicted and measured steady state smoke layer interface heights for various opening area ratios. Predictions have been made for two values of the entrainment coefficient $C_{m}=.21$ and $C_{m}=.30$ (see Eq. (1)). 
inlet area). Each figure includes the results for a $10 \mathrm{~kW}$ and a $20 \mathrm{~kW}$ fire, as shown. The agreement of the predictions with the theory is rather poor. An attempt was unsuccessful for improving the agreement of predictions with experiments by changing the propoftionality coefficient in the plume entrainment relationship from: $C_{m}=.21(2)$ to $C_{m}=.30$ (see Eq. (1)), as is indicated in figures 2 and 3 .

In this work, indeed, we have found out that this discrepancy can be attributed to the lack of applicability of existing standard relationships for entrainment rates and convective heat transfer to the present problem.

\section{ENTRAINMENT RATES AND CONVECTIVE HEAT TRANSFER IN ATRIA AND ROOM FIRES}

In the steady state experiments of the model Atrium (Eigure 1) the exhaust rate from the ceiling vent is equal to the air entrained in the plume over a length extending from the pool surface to the smoke layer interface height. We have shown that asymptotic plume entrainment relationships (including virtual origin) (1) do not reproduce these experimental results well for entrainment and this is a reason for the discrepancy between predictions and experimental results (1) as was cited earlier in this paper. This is well demonstrated in Figures $4 \mathrm{a}$ and $4 \mathrm{~b}$, by using the following method. For the asymptotic plume entrainment relationships, one would have

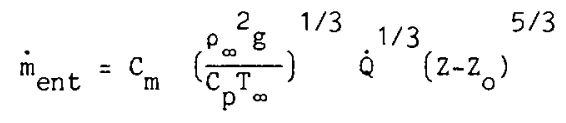

wherein $\rho_{\infty}, C_{p}, T_{\beta}$ are ambient air properties, $g$ is the gravitational acceleration, $\dot{Q}$ is the (convective) heat release rate, $Z$ is the distance from the plume origin, and $z_{0}$ is the virtual origin. (1) Such relationships would be applicable for the present data, if a plot of $\left(\dot{m}_{\text {ent }} / \dot{Q}^{1 / 3}\right)^{3 / 5}$ vs. height 2 was a straight line. Figures $4 \mathrm{a}$ and $4 \mathrm{~b}$ show this proposition is not really true.

Instead, we have found that the entrainment rate is correlated by the expression (see Figures 5a, 5b):

$$
\frac{\dot{\mathrm{m}}_{\text {ent }}}{\dot{\mathrm{Q}}^{1 / 3}}=.032 \frac{\mathrm{Z}}{\mathrm{D}}
$$

wherein the entrainment rate, $\dot{\mathrm{m}}_{\mathrm{ent}}$, is in $\mathrm{kg} / \mathrm{s}$ and the heat release rate, $\dot{Q}$, is in $\mathrm{kW} ; \mathrm{Z}$ is the vertical distance from the pool having diameter, $D$.

One should also note that the relationship in Eq. (2a) was predicted (3) to be applicable for convective thermal plume flows over a large area, small flame height fire and for $\frac{2}{D} \leq 3$. One could also generalize $\mathrm{Eq}$. (2a) by using dimensionless quantities (3);

$\frac{\dot{\mathrm{m}}_{\text {ent }}}{\rho_{\infty}\left(\frac{\mathrm{gQ}}{\rho_{\infty} \mathrm{c}_{\mathrm{p}} \mathrm{T}_{\infty}}\right)^{1 / 3} \mathrm{D} 5 / 3}=.657 \frac{\mathrm{z}}{\mathrm{D}}$ 


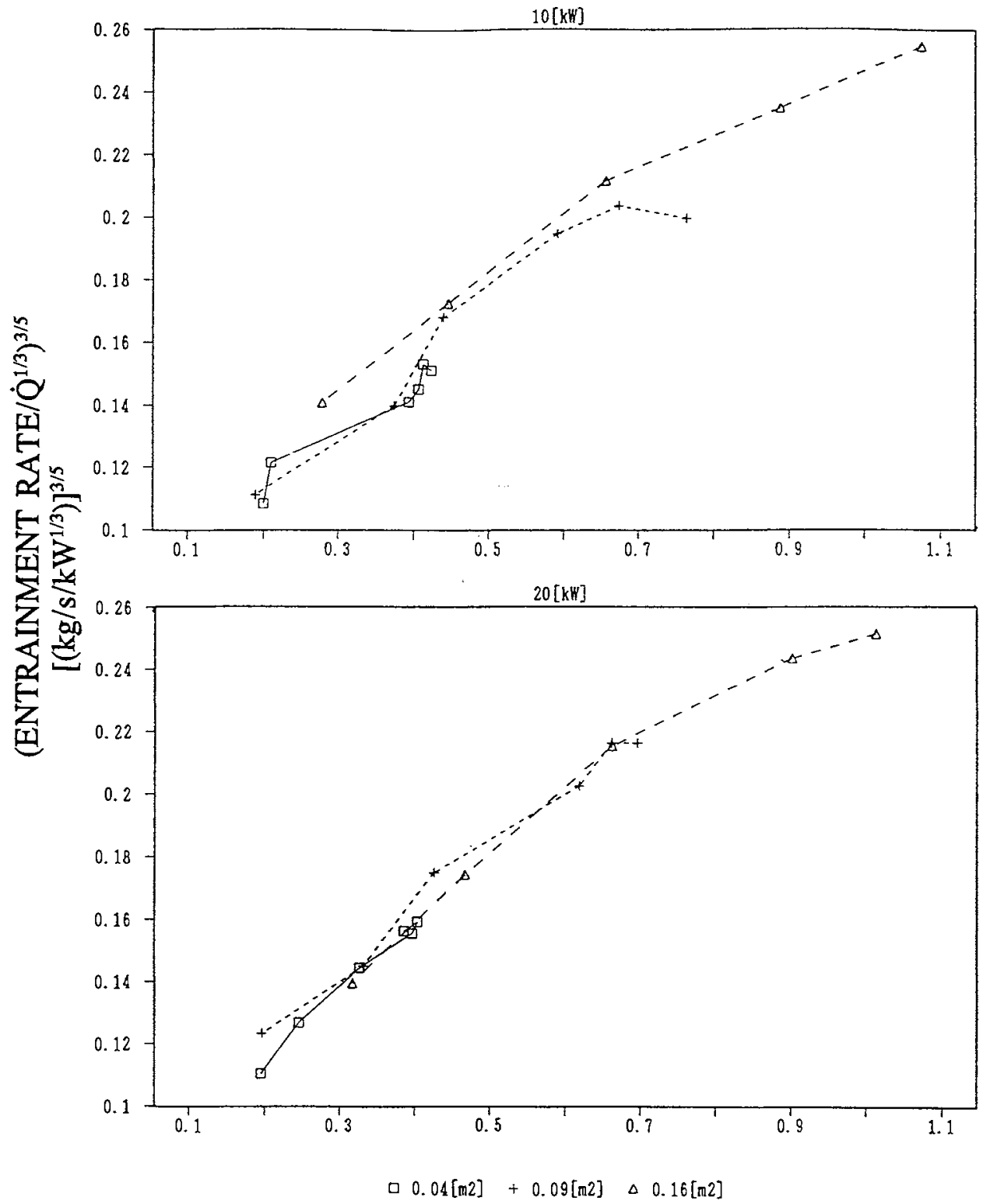

\section{$\mathrm{Z}=\mathrm{SMOKE}$ HEIGHT--0.5 (m)}

Figure 4a, Correlation method of entrainment plume data by using a standard

$4 \mathrm{~b}$ asymptotic entrainment relationship (see Eq. (1)). The results are for a plume above the flames $(=10 \mathrm{~cm})$ for a pool fire $30 \mathrm{~cm}$ in diameter and various test conditions at $10 \mathrm{~kW}$ (Fig. $4 \mathrm{a}$ ) and at $20 \mathrm{~kW}$ (Eig. 4b). Since the data are not lying on a straight line, standard entrainment relationships (i.e., Eq. (1)) do not seem to be applicable. 


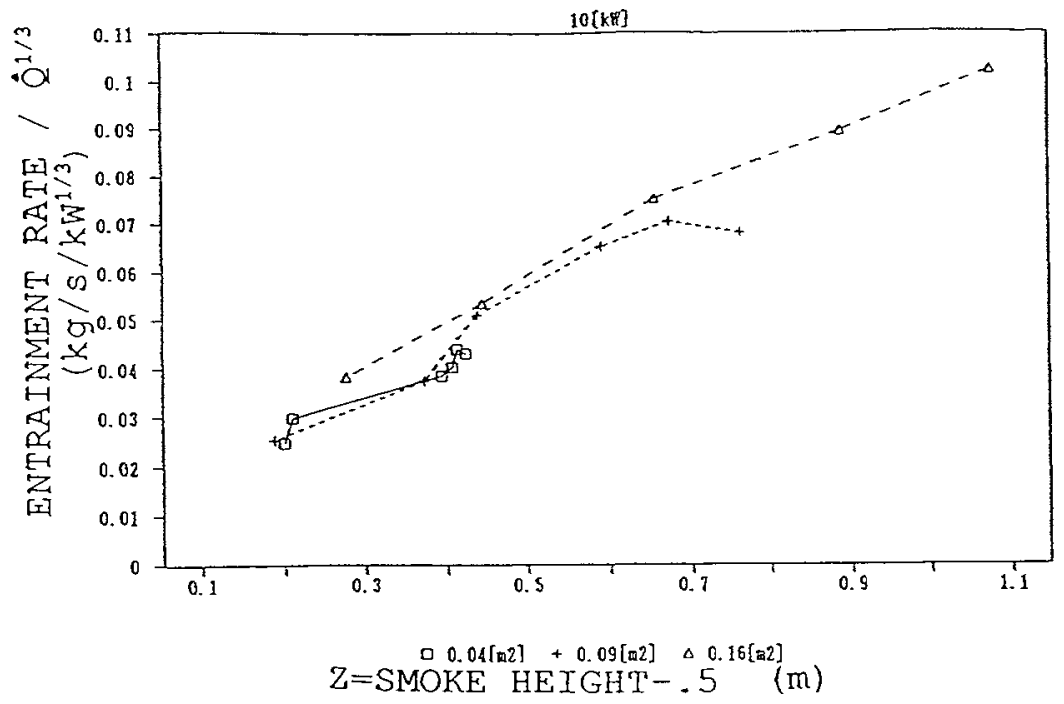

Figure 5a. New correlation for air entrainment to the plume above the flames $(=10 \mathrm{~cm}$ ) for a pool fire of diameter $30 \mathrm{~cm}$ at $10 \mathrm{~kW}$ at various test conditions (vent opening and inlet opening).

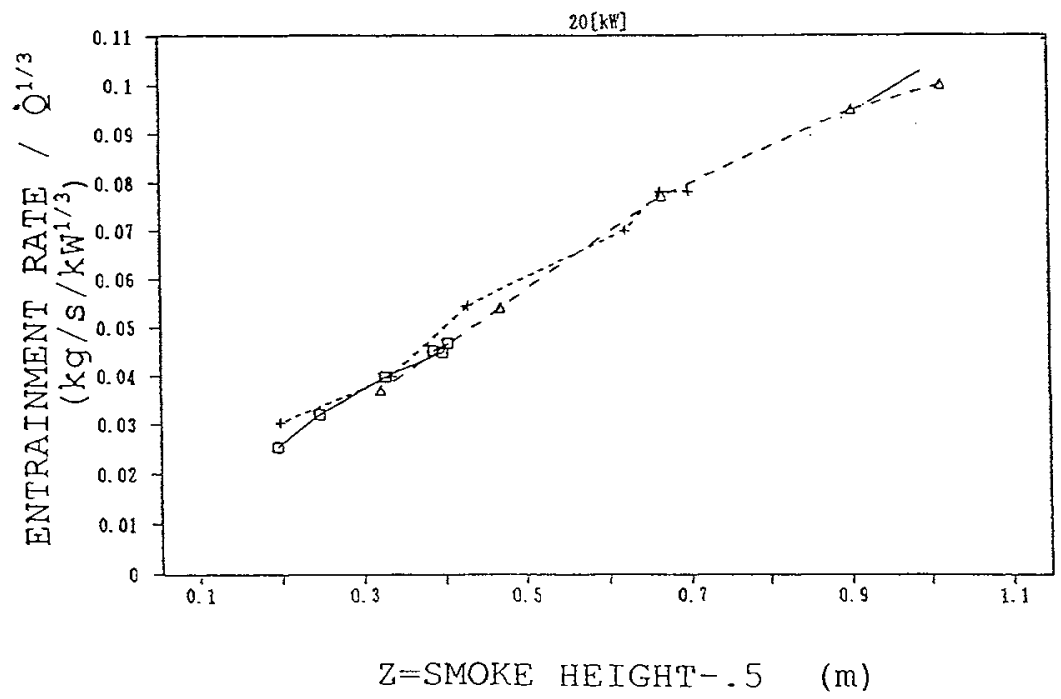

Figure 5b. Same as in Fig. $5 a$ but for a $20 \mathrm{~kW}$ fire. Data in Figures $5 a$ and 5 b closely lie on the same straight line (see Eq. (2a)). 
where $\rho_{\infty}, c_{p}, T_{\infty}$ are ambient air properties and $g$ is the gravitational acceleratioh.

The convective heat losses to the wall and to the ambient air outside the atrium can be derived from the exhaust rate and the temperature rise measurements because vertical thermocouple rack measurements (1) validate the representation of the system as a two-layer system (radiative losses and exchanges were negligible in the present experiments). It has been shown from data analysis that the convective heat losses, $Q_{L}$, are represented by the following simple expression:

$$
\frac{Q_{L}}{\left(\phi / A_{0}\right) A_{S}}=\alpha=8 \cdot 30 \cdot 10^{-2}
$$

where $Q$ is the conveotive heat release from the fire, $A$ is the horizontal area of an atrium (or a room), and $A_{S}$ is the total area (wall plus ceiling) bounding the upper hot layer. Figure 6 shows a comparison between the measured and calculated results by using Eq. (3a). Eq. (3a) can be also interpreted as a Stanton heat transfer coefficient:

$$
\begin{aligned}
& \frac{h}{\rho c_{p} \bar{u}}=8 \cdot 30 \cdot 10^{-2} \\
& \text { where } \bar{u}=\frac{\dot{m}_{\text {ent }}}{\rho A_{o}} \\
& \dot{Q}=\dot{m}_{\text {ent }} c_{p} \Delta T \\
& \frac{\dot{Q}_{L}}{A_{s}}=\dot{q}^{\prime \prime}=h \Delta T \\
& \text { and } \Delta T=T_{g, a}-T_{\infty}
\end{aligned}
$$

Note that $\mathrm{T}_{\mathrm{g}, \mathrm{a}}$ is the average adiabatic hot layer temperature (as defined by $\mathrm{Eq} .(3 \mathrm{~d}))^{\mathrm{g}}$, and $\mathrm{T}_{\infty}$ is the ambient temperature.

The correction owing to the difference between the inside wall temperature, $T_{i}$, and the (ambient) outside air temperature, $T_{\infty}$, can be calculated from a steady state heat transfer equation. The thickness of the wall is $\delta=12$ $\mathrm{mm}$ and the thermal conductivity of the wall is about (1) $\mathrm{k}=.23 \mathrm{~W} / \mathrm{mK}$. Thus,

$$
\bar{T}_{g}-T_{i}=\frac{k / \delta}{k / \delta+\frac{h_{i}}{h_{0}} k / \delta+h_{i}}\left(\bar{T}_{g}-T_{\infty}\right)
$$

wherein $h_{i}, h_{0}$ are the natural convective heat transfer coefficients to the wall on its inside and outside surfaces respectively. For turbulent natural convection, it is estimated that in the present steady state case: a) $h_{i}=h_{o}$ and b) $h_{i} \simeq 4 \mathrm{~W} / \mathrm{m}^{2} K$. Therefore, Eq. (4a) gives 


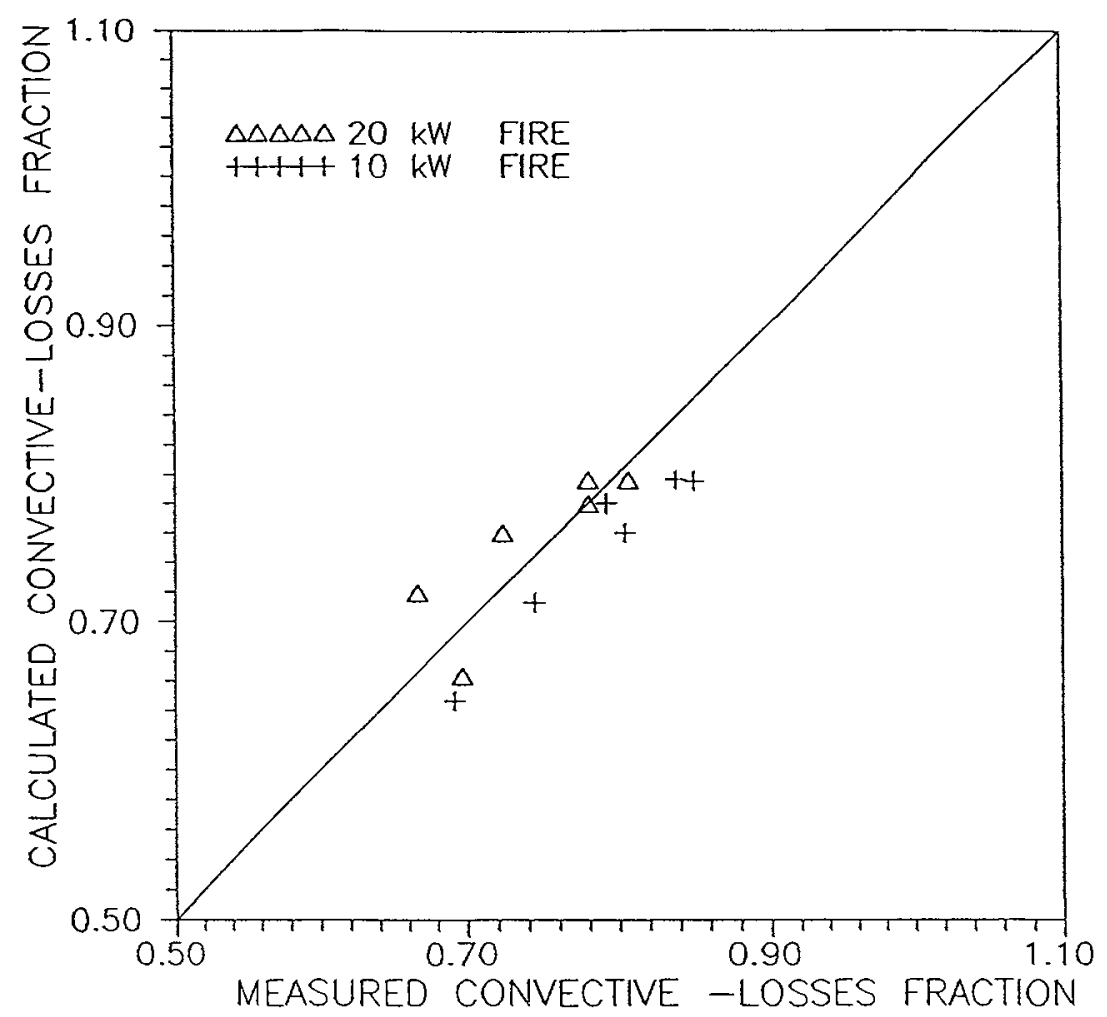

Figure 6. Predicted and measured convective heat losses for the model Atria tests, using the present heat transfer correlation, Eq. $3 a$. 
Notice that $\overline{\mathrm{T}}_{\mathrm{g}}$ in Eqs. ( $4 \mathrm{a}$ ) and $(4 \mathrm{~b}$ ) is the average hot layer temperature including heat losses; it is different from the average adiabatic hot layer temperature as defined by Eq. (3d), namely:

$$
\frac{\overline{\mathrm{T}}_{\mathrm{g}}-\mathrm{T}_{\infty}}{\mathrm{T}_{\mathrm{g}, \mathrm{a}}-\mathrm{T}_{\infty}}=\frac{\dot{\mathrm{Q}}-\dot{\mathrm{Q}}_{\mathrm{L}}}{\dot{\mathrm{Q}}}=2
$$

for the present tests (see Figure 6). By using Eqs. (4b) and (4c), one finally obtains the following relationship

$$
\frac{T_{g, a}-T_{i}}{T_{g, a}-T_{\infty}}=.89
$$

It is possible now to modify Eq. (3b) in order to account for the increased wall temperature over the (ambient) outside air temperature:

$$
\frac{h}{\rho c_{p} \bar{u}}=\frac{8 \cdot 3 \cdot 10^{-2}}{.89}=9 \cdot 32 \cdot 10^{-2}
$$

where the heat loss is defined now as:

$$
\frac{\dot{Q}_{L}}{A_{S}}=\dot{q}^{\prime \prime}=h\left(T_{g, a}-T_{i}\right)
$$

and Eqs. (3c), (3d) and (3f) are still applicable.

\section{CONCLUSIONS}

A most noteworthy feature of the present results is that they are the first direct measurements and correlations of entrainment rates and overall convective heat losses in a compartment fire. Thus, they are invaluable in validating and comparing zone models for smoke movement.

The experimental results from the present study allowed us to make the following contributions to the modeling of compartment fires: a) For thermal plumes originating from small, large area fires, a new expression for the entrainment rate was established applicable above the flame tip and up to three times the pool diameter (Eq. (2a)).; b) An experimentally established correlation for the convective heat losses to the walls in a compartment fire fire was also developed (Eq. (3a)).

\section{REFERENCES}

1. Ishino, 0 . and Tanaka, T., "Efficiency of Smoke Control of Atria by Natural Venting," UJNR Meeting, November 1992. 
2. Zukoski, E.E., Entrainment and Flame Geometry of Fire Plumes, NBS, NBSGCR-82-402, 1982 .

3. Delichatsios, M.A., "Air Entrainment into Buoyant Jet Flames and Pool Fires," Combustion and Flame, 70:33-46, 1987. 